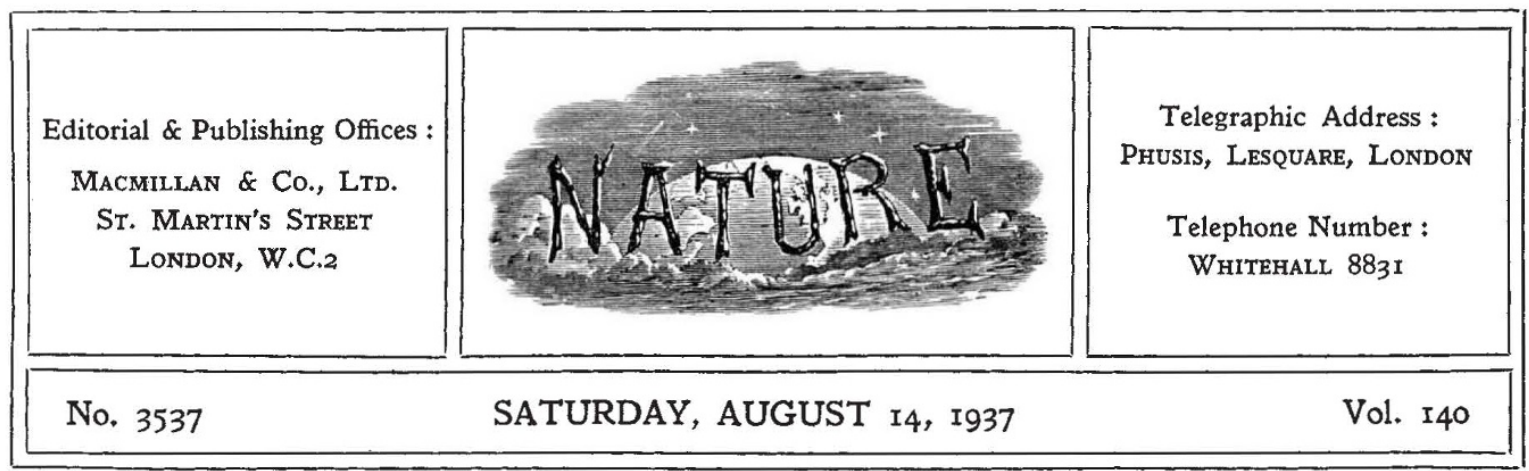

\title{
Science in Social Services
}

$\mathrm{I}^{\mathrm{N}}$ his farewell address on June 24 to the London School of Economics, Sir William Beveridge emphasized the need for both observation and detachment in the social sciences. Failure to be scientific in method and detachment on the part of both economists and statesmen, he said, had largely been responsible for the tardy development or recognition of the social sciences, alike in the neglect of observation of facts as the basis of theories and as the control of theories, and in the lack of detachment from partisan actions and the giving of judgment on controversial political issues. The social services of Great Britain might well have been cited by Sir William Beveridge to illustrate his point. They continue to grow piecemeal, and every session Parliament adds something to the imposing structure; but it is nearly thirty years since the last comprehensive inquiry into public social provision in Great Britain was made. Continually, however, we witness particular aspects of the social services criticized strongly to prove or disprove some political tenet or preconceived idea, and it is rare indeed to find them considered in relation to a comprehensive and well-defined social policy.

The report on the social services which has just been issued by PEP (Political and Economic Planning) accordingly meets a definite need as well as provides a noteworthy example of the type of impartial and comprehensive analysis of the facts desiderated by Sir William Beveridge. The report has the freedom from preconceptions which characterizes the investigations of $\mathrm{P} \mathrm{E} \mathrm{P}$ and gives us a comprehensive and detailed examination of each of the social services.
With some of these individual social services, which are grouped in three categories-namely, constructive community services, such as education and public health and the employment exchanges; social insurance services, such as national health insurance, unemployment insur. ance, widows', orphans' and old-age contributory pensions, as well as workmen's compensation; and social assistance services, such as non-contributory old-age pensions, unemployment and public assistance-scientific workers may have their own particular contact as individual citizens. With the collective review of the services as a system, the mapping of the ground they cover, and the intervening gaps, as well as with the indications which this report affords of trends in policy which are not yet fully developed in the existing socia] services, scientific workers will, however, have a keen, if not a professional, interest.

The admirable survey and analysis which are provided in this report are primarily a stimulus to further constructive thinking; and opinions in some matters that have sometimes ranked as established convictions will require re-examination by unprejudiced students. Despite the great increase in the last thirty years of expenditure on social services, which now reaches the sum of $£ 400,000,000$ a year, that is, nearly $£ 9$ a head, or about a tenth of the national income of 1934, 71 per cent of, which is financed out of rates and taxes, the report shows clearly that there has been no spectacular transfer of wealth from rich to poor. Indirect taxation of the working classes has increased side-by-side with the direct taxation of the well-to-do. 
The main argument of the report is not that we should begin to economize on our social services but that we should plan them better. At present they are the result of piecemeal political and administrative improvisations which need replacing by a more deliberate social service policy, a continued review with a programme of priorities and the filling of gaps. Many of these gaps, as well as serious anomalies and defects, wide disparities, and abuses, appearing unchecked in our present system, are duly pointed out in the report, which leaves no doubt of the room for reform. But the report does more than this. It assists the emergence of a mature philosophy and a broad strategy of the social services, and thus the replacement of fairly strong but largely unconscious tendency by conscious purpose.

This establishment of guiding principles, and of authority to ensure their observance in practice, is best secured not by a Royal Commission, which is regarded as too cumbersome, but by the establishment of a Social Service Statutory Committee, acting as an advisory general headquarters staff. The value of this type of detached examination and criticism is demonstrated by the experience of the Unemployment Insurance Statutory Committee and of the Law Revision Committee. The suggested committee would have three main duties: to study the basic principles of the services; to promote efficient and economic working, indicating any needful change of administrative and financial structure ; and to direct attention to anomalies and gaps, making remedial proposals.

Scientific workers will be quick to recognize in this suggestion something of the ideas expounded by General Smuts in his Sidgwick Memorial Lecture on "Democracy"; and this further plea for an extension of scientific method and inquiry into controversial matters which should be settled on a basis of fact, and not prejudice, will be welcomed by them. Equally, too, the report makes clear the impossibility of isolating politically the social services. Economic policy, social service policy, and industrial wage policy are closely interlocked. Under our present health insurance system bad industrial organization may be persistently subsidized. The powers provided under the National Health Insurance Act to survey the health of local communities, and penalize employers responsible for high sickness rates, have never been used, and certain factories and offices continue to be so unsatisfactorily arranged or operated that they give rise to excessive numbers of sickness claims.

The increasing part which scientific workers take in the administrative side of industry gives them special responsibilities in these matters, and the report also comments on the failure of those in charge of the great public social insurances of the United Kingdom to be alive to these questions and to take the broad view of their functions in helping to reduce accidents and disease, which some private enterprise insurance companies have done. Dereliction of duty of this type is one of the prime concerns of associations of professional workers, and it is clear that such associations need much more general support from the rank and file of the professions and also continued stimulus if their functions are to be fully and wisely discharged.

The clear thinking of this report, no less than its analysis of the facts, can scarcely fail to be highly suggestive to many scientific and professional workers and to stimulate further thought and effort in many fields. There are, however, other matters of immediate personal concern to scientific workers on which the report touches. For example, in its summing-up of the problem of the family, the report favours the introduction into the general wage and salary system of Great Britain of the principle of family allowances, to which social reformers as well as industrialists have been largely opposed. The report argues that public social services must either consciously be used as an agency for adjusting burdens as between large and small families, or else they will tend more and more to reinforce those commercial and other agencies which are steadily making it less attractive for the average citizen to rear a family.

A second matter raised by the report, which is also of direct concern to scientific workers, is that of the personnel of social service administration. On this subject it makes two main criticisms. The preparation of the report has revealed a serious amount of compartmental out. look and experience as characterizing those engaged in the administration of the social services at this stage. There are many men and women who are well informed about particular branches or aspects, but it is rare to find anyone who has given much thought to the inter-relations of the social services with one another, or to their repercussions on social or economic life and to their liner of development. 
One of the first needs of to-day is the breakdown of this sectionalism and departmentalism; those concerned with particular aspects or subjects should start thinking intensively about the place of their own specialism in the whole scheme of the social services. In part, this is a matter in which professional associations could exert a useful influence, and their direct contribution to the effective co-ordination of the social services with one another, and with national policy as a whole, or to the re-examination of the forms of democratic control and public accountability in the social services, should not be negligible. In part, however, it is a matter of recruitment, and here the report refers to the failure to implement the recommendations of the Departmental Committee on the Recruitment and Training of Local Government Officers, in its report issued in 1935.

The need for improved recruitment and training is not, however, confined to the local government service. Although the quality of the personnel is often of the highest order, existing arrangements for the recruitment and training of officers for certain forms of social work, for example, the work of the Unemployment Assistance Board, are not entirely satisfactory. Apart from the importance of recruiting officers for the social services whose training and outlook raises them above departmentalism and stimulates constructive thought about the place of their special work in the social services and policy generally, the formal traintng requirements of various departments or branches of the service are very narrow and overweighted by technical questions arising out of statutes, regulations and codes of instructions.

The report suggests that there is a real need for a comprehensive course of training in social case work to be taken by all who wish to engage in this career; and it is clear that, in this matter also, professional associations could offer a very useful contribution. Moreover, the report shows that there are very important spheres of social service in which, whether because of their experimental or controversial nature at the time, the exceptional freedom of opinion and experiment demanded for teaching or research, or the individual attention required for intimate personal problems, voluntary organizations are not only more appropriate but also may have essential functions to fulfil.

At a time when scientific workers generally are considering so closely the social consequences of their work, the P E P report not only provides a very stimulating survey of the field which indicates definite directions for further research, but also issues a challenge to really practical efforts which can scarcely be ignored by such workers if their interest in social affairs and social science is sincere.

\section{History of Elementary Mathematics}

Geschichte der Elementar-Mathematik in systematischer Darstellung :

mit besonderer Berücksichtigung der Fachwörter. Von Dr. Johannes Tropfke. Band 3: Proportionen, Gleichungen. Dritte, verbesserte und vermehrte Auflage. Pp. iv +239 . (Berlin und Leipzig: Walter de Gruyter und Co., 1937.) 10 gold marks.

A LL who are interested in the history of matheA matics will be delighted to see that Dr. Tropfke continues to make progress with the publication of the third edition of this invaluable work which, in the form it took in the second edition, has long been an indispensable book of reference. It is nearly thirty-five years since the date of the preface to the first edition (summer 1902) in two volumes; the second edition, much enlarged and modified in arrangement, came out in seven volumes or parts between the years 1920 and 1924 , and grew to a compass of nearly 1,300 pages in all. The third edition, in consequence of the mass of fresh material which has accumulated since 1924 through new discoveries and researches, bids fair to show an increase in size of one third or thereabouts. It is gratifying to find that each volume as it comes out brings the subject of it up to date. There are many references in the present volume to books and papers of date so recent as 1936 . Some slight inconvenience will be caused by the fact that, owing doubtless to the amount of work involved, the volumes are appearing at considerable intervals-vol. 1 appeared in 1930, vol. 2 in 1933, and vol. 3 in 1937 - so that, as each volume comes out necessitating a multitude of fresh references, the references in the earlier volumes 